\title{
Nilai Tukar Dan Inflasi Terhadap Return Saham Melalui Kinerja Keuangan
}

\author{
Ati Retna Sari1, Doni Wirshandono Yogivaria ${ }^{2}$ \\ Program Studi Akuntansi, Fakultas Ekonomika Dan Bisnis, \\ Universitas PGRI Kanjuruhan Malang, Indonesia
}

\author{
Corresponding Author \\ Nama Penulis : Ati Retna Sari \\ E-mail : atiretnasari@unikama.ac.id
}

\begin{abstract}
Abstrak
Return saham merupakan hasil dari kegiatan investasi yang dilakukan oleh investor. Tujuan dari penelitian ini adalah untuk mengetahui pengaruh nilai tukar dan informasi terhadap return saham melalui Kinerja Keuangan. Kinerja keuangan dalam penelitian ini adalah ROE Populasi penelitian ini adalah perusahaan manufaktur yang terdaftar di Bursa Efek Indonesia periode 2017-2019 Pengambilan sampel menggunakan teknik proposive sampling. Ada 20 sampel penelitian. Teknik pengumpulan data dengan dokumentasi. Teknik analisis data menggunakan Samat PLS. Hasil penelitian menunjukkan nilai tukar berpengaruh terhadap return saham melalui kinerja keuangan. Inflasi mempengaruhi return saham bukan melalui kinerja keuangan. Implikasi dari penelitian ini adalah investor dan calon investor harus memperhatikan rasio inflasi saat ini juga sebagai kinerja keuangan agar dapat menghasilkan return yang maksimal
\end{abstract}

\section{Kata Kunci: Nilai Tukar, Inflasi, Return Saham, ROE}

\section{Abstract}

Return of shares is the result of investment activities conducted by investors. The purpose of this study is to determinde the influences of exchange rates and infation on stocks returns through Financial Performance. Financial kenerja in this study adala ROE Population this research is a manufacturing company listed on the Indonesia Stock Exchanges period 2017-2019 Sampling using proposive sampling techniques. There are 20 research samples. Data collection techniques with documentation. Data analysis techniques using Samart PLS. The results showeds the exchange rate had an effect on the return of shares through financial performance. Inflation affects stock returns not through financial performance. The implications of this research is that investors and prospective invertors should pay attention to the current inflation ratio as well as financial performance in order to generate maximum returns

Keywords: Exchange Rates, Inflation, Stock Returns, ROE 
Ati Retna Sari ${ }^{1}$, Doni Wirshandono Yogivaria ${ }^{2}$, Nilai Tukar Dan Inflasi Terhadap Return Saham Melalui

\section{PENDAHULUAN}

Kinerja Keuangan

Tujuan investor berinvestasi adalah untuk mendapatkan laba..investor berinvestasi pada pasar modal untuk mendapatkan gain dan deviden. Alasan berinvestasi adalah untuk Alasan investor untuk berinvestasi adalah mendapatkan keuntungan ekonomi di masa depan,mengurangi inflasi dan pajak (Tandelilin, 2017). Keputusan investor untuk berinvestasi di pasar modal dilandasi pengetahuan analsis yang ada dipasar modal, hal ini dilakukan agar investor dapat meminimalkan risiko kerugian. Ada dua analis yang harus dilakukan investor sebelum berinvestasi adalah analis teknikal dan analisi fundamental. Analis teknikal merupakan analis fluktuasi harga saham dalam rentang waktu tertentu. Hasil analis teknikal dapat dipakai dalam melakukan pembelian maupun penjualan dengan tujuan mendapatkan keuntungan. Analis fundamental merupakan analisyang memperhitungkan beberapa faktor sebelum mengambil keputusan membeli atau menjual. Faktor faktor yang dipertimbangkan dalam analis fundamental adalah kinerja perusahaan,persaingan usaha, analis ekonomi baik mikro maupun makro. Hasil analis fundamental adalah investor dapat mengetahui secara pasti bahwa kondisi perusahaan yang baik. Kondisi perusahaan yang baik merupak sinyal yang baik untuk berinvestasi.

Return saham ialah hasil atas kegiatan berinvestasi. Return saham bisa berupa deviden atas investasi saham sertapenghasilan bunga dari investasi di oblogasi. Prosentase Return saham yang meningkat yakni sinyal yang baik bagi investor serta calon investor untuk menanamkan modalnya di perusahan dengan membeli saham. Investor yang baik dapat memperkirakan hasil dari investasinya (Hartono, 2017).

Nilai tukar ialah kurs antara dua negara. Kurs yakni tingkat harga yang telah tersepakati kedua negara untuk dilakukannya transaksi penjualan. Nilai tukar merupakan alat ukur untuk menilai kekuatan ekonomi suatu negara. Infasi merupakan suatu keadaan terjadi perubahan naiknya harga barang serta jasa yang berlangsung terus nenerus dalam jangka waktu tertentu.Dampak dari inflasi adalah turunnya nilai uang. Besar kecilnya dampak infasi tergantung pada prosentasenya. Besar kecil inflasi akan sangat mempengaruhi perekonomian suatu negara.

Faktor yang diduga dapat memberikan pengaruh return saham adalah ROE. Penilain kinerja keuangan dengan menggunakan rasio keuangan ROE. ROE ialah rasio profitabilitas yang digunakan dalam pengukuranmampunyaemitendalam menghasilkan laba bagi investor. ROE yang meningkat mendekati 100\% menandakan bahwa setiap Rp 1 ekuitas menghasilkan laba Rp 1 dari laba bersih.

Hasil peneltian (Kwofie et al., 2018) di Ghana , (Kwofie et al., 2018), menjelaskan infalsi serta nilai tukar berpengaruh pada return saham. (Al-Abdallah et al., n.d.)Di Jordan menjelaskan Inflasi berpengaruh pada retun saham, nilai tukar tidak berpengaruh pada return saham.(Kaur, 2016), di India menjelaskan inflasi berpengaruh pada return saham, nilai tukar tidak berpengaruh pada return saham. Hasil (Okechukwu, Mbadike Geoffrey, 2019), menunjukkan suku bunga memiliki hubungan negatif dengan pengembalian pasar saham, sedangkan tingkat inflasi serta nilai tukar memiliki hubungan positif dengan pengembalian pasar saham.

\section{TUJUAN PENELITIAN}

Tujuan penelitian yakni untuk menguji serta mengetahui apakah nilai tukar dan infasi berpengaruh terhadap return saham dimediasi Kinerja Keuangan. 
Ati Retna Sari ${ }^{1}$, Doni Wirshandono Yogivaria ${ }^{2}$, Nilai Tukar Dan Inflasi Terhadap Return Saham Melalui Kinerja Keuangan

\section{METODE}

Metode peneltian yang digunakan adalah metode kuantitatif. Tempat penelitian pada galeri investasi Universitas PGRI Kanjuruhan Malang pada tahun 2017-2019. Populasi penelitianya semua perusahaan manufaktur yang terdaftar di BEI tahun 2017- 2019. Teknik pengampilan sampel ialah teknik purposive sampling. Sampel yang terpakai yakni 20 emiten. Data penelitian ialah data kuantitatif yang berupa data sekunder. Teknik pengumpulan data yakni dokumentasi dengan Smart PLS sebagai teknik analisis datanya.

\section{HASILDAN PEMBAHASAN}

\section{Tabel 1. Uji Validitas dan Reliabilitas}

\section{Construct Reliability and Validity}

\begin{tabular}{|c|c|c|c|c|c|c|c|c|}
\hline \multirow[t]{2}{*}{ Matrix } & \multirow[t]{2}{*}{ 搡品 } & Cronbach's Alpha & 拐荈 rho_A & 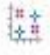 & \multicolumn{2}{|c|}{ Composite Reliability } & \multicolumn{2}{|c|}{ 蛀 Average Variance Extracted } \\
\hline & & Cronbach's Al... & & O_A & Composite Rel... & Ave & erage Varian... & \\
\hline inflasi & & 1.000 & & 000 & 1.000 & & 1.000 & \\
\hline nilai tukar & & 1.000 & & 000 & 1.000 & & 1.000 & \\
\hline return sahan & & 1.000 & & 000 & 1.000 & & 1.000 & \\
\hline roe & & 1.000 & & 000 & 1.000 & & 1.000 & \\
\hline
\end{tabular}

\section{Sumber data di olah 2020}

Sesuai tabel 1 nilai Cronbach's Alpha, Rho_A, Composite reliabilityserta AVE lebih dari 0.07 maka data dalam penelitian ini dinyatakan reliabel dan valid.

Tabel 2. Pengujian Goodness of Fit

\begin{tabular}{|c|l|c|}
\hline Model & \multicolumn{1}{|c|}{ Varibel Endogen } & R_Sguare \\
\hline 1 & Return Saham & 0.519 \\
\hline 2 & Kinerja keuangan & 0.397 \\
\hline
\end{tabular}

Sumber data di olah 2020

$$
\begin{aligned}
\text { Q-Square } & =1-[(1-\mathrm{R} 21) \times(1-\mathrm{R} 22)] \\
& =1-[(1-0.5192) \times(1-0.3972)] \\
& =1-[(1-0.269) \times(1-0.158)] \\
& =1-(0.731 \times 0.842) \\
& =1-0.616 \\
& =0.384
\end{aligned}
$$


Ati Retna Sari ${ }^{1}$, Doni Wirshandono Yogivaria ${ }^{2}$, Nilai Tukar Dan Inflasi Terhadap Return Saham Melalui Kinerja Keuangan

Berdasarkan Tabel 2, menjelaskan nilai predictive-relevance 0,384 atau 38,4\%. Nilai predictive relevance $38,4 \%$ berindikasi informasi yang didapatkan pada data $38,4 \%$ bisa dijelaskan oleh model tersebut.

Tabel 3 Pengujian Hipotesis

\begin{tabular}{|l|c|c|c|c|}
\hline \multicolumn{1}{|c|}{ Variabel } & $\begin{array}{c}\text { Orginals } \\
\text { ampel }\end{array}$ & T statistik & P value & Simpulan \\
\hline Nilai Tukar ---------Return & 0.283 & 2.704 & 0.000 & diterima \\
\hline Inflasi --------------Return Saham & -0.588 & 5.659 & 0.009 & diterima \\
\hline ROE----------------Return & 0.243 & 2.238 & 0.021 & diterima \\
Saham & & & & diterima \\
\hline Nilai Tukar---------ROE & 0.355 & 2.306 & 0.025 & diterima \\
\hline Inflsi ---------------ROE & -0.320 & 2.077 & 0.042 & diterima \\
\hline Nilai Tukar-----ROE---Return & 0.335 & 3.528 & 0.000 & \\
\hline Saham & & & & \\
\hline Inflasi------ROE------Return & -0.110 & 1.502 & 0.134 & ditolak \\
\hline Saham & & & & \\
\hline
\end{tabular}

Sumber data di olah 2020

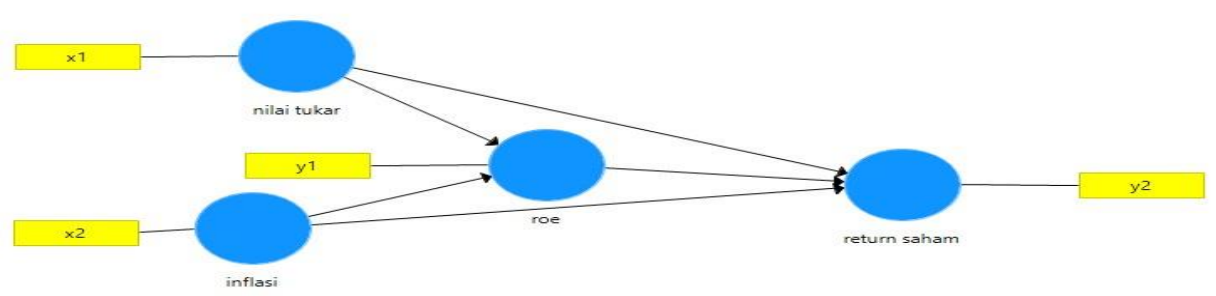

Sumber data di olah 2020

Gambar 2. Diagram Jalur Model Struktural dalam PLS 
Ati Retna Sari ${ }^{1}$, Doni Wirshandono Yogivaria ${ }^{2}$, Nilai Tukar Dan Inflasi Terhadap Return Saham Melalui Kinerja Keuangan

\section{PEMBAHASAN}

\section{Nilai tukarberpengaruhpada return saham}

Hasil menujukan nilai tukar berpengaruh pada return saham. Tinggi rendahnya nilai tukar berpengaruh pada return saham. Nilai tukar yang berlakuakan sangat mempengaruhi return saham yang akan diterima investor. Menurut (Tandelilin, 2017), nilai Kurs inilah sebagai faktor yang memprediksi aktivitas pada pasar saham ataupun pasar uang dikarenakan investor lebih berhati-hati dalam menjalankan investasi dikarenakan jika kurs naik dan biaya bahan baku meningkatakan menyebabkan turunnya laba sehingga akan memberikan dampak pula pada return saham yang diterima para investor.

Hasil penelitian (Okechukwu, Mbadike Geoffrey, 2019), (Kwofie et al., 2018), (Edison et al., 2017), menjelaskan nilai tukar berpengaruh pada return saham. Hasil riset bertolak belakang dengan (Al-Abdallah et al., n.d.), (Kaur, 2016), yang menejlaskan nilai tukar tidak berpengaruh pada return saham.

\section{Inflasi berpengaruh terhadap return saham}

Hasil penelitian inflasi pada return saham menunjukan bahwa inflasi berpengaruh pada return saham. Tinggi rendahnya rasio inflasi bisa memberikan pengaruh untuk return saham. Menurut (Tandelilin, 2017), inflasi serta return saham mempunyai keterkaitan negatif, bermakna jika inflasi naik maka return turun.

Hasil penelitian sesuai dengan (Kwofie et al., 2018)di Ghana, (Kaur, 2016), (Al-Abdallah et al., n.d.), serta(Amrillah, 2016), menjelaskan inflasi secara langsung memiliki pengaruh negative pada return saham. Sesuai dengan (Afiyati \& Topowijono, 2018), menejalskan secarasimultan variable inflasi, BI rate serta nilai tukar berpengaruh pada return saham. Hasil riset tidak sejalan dengan(Okechukwu, Mbadike Geoffrey, 2019),inflasi mempunyai hubungan positif pada return saham.

\section{Kinerja Keuangan berpengaruh terhadap Return Saham}

Hasil menunjukakan kinerja keuangan berpengaruh pada return saham. Ini berarti tingi rendahnya kinerja keuangan mempengaruhi return saham. Hal ini sesuai dengan (Fahmi, 2014), ROE merupakan mampunya perusahaan dalam diperolehnya laba bagi pemegang saham. Bagian laba emiten yang dibagikan ke investor berupa return saham. Besar kecilnya return saham dipengaruhi besar kecilnya ROE.

Hasil penelitianmendukungpenelitian(Ramadhan \& Dhea, 2019), yang menyatakan kinerja keuangan berpengaruh pada return saham. ROE memberikan pengaruh pada investor dalam pengambilan keputusan investasinya. Penelitian ini tidak sesuai dengan(Aisah, Ayu Nurhayani Kastawan, 2016), yang menjelaskan ROE tidak berpengaruh pada return saham.

\section{Nilai Tukar Berpengaruh Terhadap Kinerja Keuangan}

Hasil penelitian ini menjelaskan nilai tukar berpengaruh pada kinerja keuangan. Hal in ibermakna makin tinggi nilai tukar maka makin tinggi kinerja keuangan yang di ukur dengan ROE. Perusahan yang memiliki hutang dalam bentuk dolar bisa berdampak pada menurunnya kinerja 
Ati Retna Sari ${ }^{1}$, Doni Wirshandono Yogivaria ${ }^{2}$, Nilai Tukar Dan Inflasi Terhadap Return Saham Melalui Kinerja Keuangan keuangan perusahaaan. Hal ini disebabkan karena melemahnya nitai tukar terhadap dolar. Beban perusahaan untuk membayar hutang semakin tinggi.

Hasil penelitian sesuai dengan (Kwofie et al., 2018), (Edison et al., 2017), menjelaskan nilai tukar berpengaruh pada kinerja keuangan. Perubahan pada kurs juga memengaruhi terbentuknya harga barang maupun jasa impor-ekspor.

\section{Inflasi Berpengaruh Terhadap Kinerja Keuangan}

Pengaruh inflasi pada kinerja keuangan (ROE)) secara langsung menjelaskan inflasi berpengaruh pada kinerja keuangan Tinggi rendahnya inflasi akan mempengaruhi kinerja keuangan Hal tersebut sejalan dengan (Fahmi, 2014), menjelaskan bagi pemilik saham merupakah hal krusial dalam penurunan inflasi disebabkan meningkatnya inflasi secara relative bisa berdampak negative bagi pemodal.

Hasil penelitian sesuai dengan (Amrillah, 2016), menjelaskan inflasi secara langsung mempunyai pengaruh negative pada return saham. Sama halnya riset (Afiyati \& Topowijono, 2018), menjelaskan secara bersamaan variable inflasi, BI rate serta nilai tukar berpengaruh pada return saham.

\section{Nilai Tukar Terhadap Return Saham Melalui Kinerja Keuangan}

Nilai tukar berpengaruh pada return saham dimediasi kinerja keuangan. Kinerja keuangan yang diproksi ROE dapat berpengaruh tidak langsung dalam keterkaitan nilai tukar dengan return saham. Nilai tukar yang baik dengan ROE yang naik akan meningkatkan return saham. Hal ini akan direspon sangat baik oleh investor maupun calon investor.

Menurut (Rudianto, 2013), kurs ialah nilai tukar dengan suatu mata uang dengan mata uang negara lain. Berubahnya nilai tukar bisa memberikan pengaruh operasional perusahaan, nilai perusahaan, serta berpengaruhnya bagi internal emiten.

\section{Infasi Berpengaruh Terhadap Return Saham Melalui Kinerja Keuangan}

Hasil penelitian menjelaskan inflasi berpengaruh pada return saham tidak melalui kinerja keuangan. Kinerja keuangan yang teraproksi dengan ROE tidak berpengaruh pada hubungan inflasi dengan return saham. Naiknya ROE belum memberikan pengaruh secara tidak langsung pada kondisi inflasi pada return saham.

Hasil tidak sejalan dengan (Kurniasari, 2018), hasil (Uji t) inflasi serta suku bunga mempunyai pengaruh secara langsung pada return saham. ROA tidak mempunyai pengaruh secara langsung pada return. Inflasi berpengaruh secara tidak langsung pada return saham dimediasi ROA.

\section{KESIMPULAN}

Sesuai hasil pengujian nilai tukar serta inflasi pada return saham melalu kinerja keuangan dapat disimpulkan sebagai berikut: Nilai tukar berpengaruh pada return saham. Naik turunnya nilai tukar mempengarui besar kecilnya retun yang diterima investor.Inflasi berpengaruh pada return saham. Besar kecilnya rasio inflasi mempengaruhi besar kecilnya return saham yang diterima investor.Kinerja keuangan berpengaruh pada return saham. makin baik kinerja keuangan maka akan semakin besar return saham yang akan diterima investor. Nilai tukar berpengaruh terhadap kinerja 
Ati Retna Sari ${ }^{1}$, Doni Wirshandono Yogivaria ${ }^{2}$, Nilai Tukar Dan Inflasi Terhadap Return Saham Melalui Kinerja Keuangan keuangan. Nilai tukar yang baikqadalah nilai tukar yang tidak berfluktuasi akan berdampak baikpada kinerja keuangan. Infasi berpengaruh terhadap kinerja keuangan. Besar kecilnya rasio inflasi akan mempengaruhi kinerja perusahaan. Nilai tukar berpengaruh pada return saham dimediasi kinerja keuangan. Dari penjelasan, nilai tukar bisa mempengaruhi return saham dengan digunakannya kinerja keuangan yang teraproksi ROE. Bermakna, ROE tidak membuktikan mempunyaifungsi sebagai variabel intervening. Inflasi berpengaruh pada return saham dimediasi kinerja keuangan.Dari hasil penelitian tersebut menjelaskan ROE tidak terbukti berfungsi sebagai variabel intervening

\section{DAFTAR PUSTAKA}

Afiyati, H. T., \& Topowijono. (2018). Pengaruh Inflasi, BI Rate dan Nilai Tukar pada Return (Studi Pada Perusahaan Subsektor Food E Beverages yang Terdaftardi Bursa Efek Indonesia Periode 2013-2016).

Aisah, Ayu Nurhayani Kastawan, M. (2016). Pengaruh ROE, EPS, Firm Size, dan Operating Cash Flow Pada Return Saham. Jurnal Manajemen.

Al-Abdallah, Yousef, S., Aljarayesh, I. A., \& Nada. (n.d.). Influence Of Interest Rate, Exchanges Rates And Inflation On common Stock Retuns Of Amman Stock Exchange Jordan. International Journal of Economics, Commerce and Management, IJECM; ISS.

Amrillah, M. F. (2016). Pengaruh Nilai Tukar (Kurs), Inflasi serta Pertumbuhan Ekonomi pada Returnn Saham. Jurnal Valuta, Vol 2, No.

Edison, A., Sugiartiningsih, \& Aprialiana, T. (2017). The Effect of Inflation, BI Rate, and Rupiah Exchange Rate on Stock Returns and Its Effect on ROI. 8th Wiedyatama International Seminar on Sustainability.

Fahmi, I. (2014). Analisa Kinerja Keuangan. Alfabeta.

Hartono, J. (2017). Teori Portofolio dan Analisis Investasi Edisi kesebelas. BPFE-Yogyakarta.

Kaur, M. (2016). An Impactd Of Inflations And Exchanges Rate On Stock Rwturns: Evidence FromIndia. Scholarly Research Journal for Interdisciplinary Studies, Online ISSN 2278-8808, SJIF 2016 6.17. www.srjis.com

Kurniasari, W. (2018). Pengaruh Inflasi dan Suku Bunga terhadap Return Saham dengan Profitabilitas sebagai Variabel Intervening di Perbankan yang Terdaftar diBursa Efek Indonesia Tahun 20132015. Journal Of Accounting Science, Vol. 2 No.

Kwofie, C., Ansah, K., \& Richaed. (2018). A Study of the Effect of Inflation and Exchange Rate on Stock Market Returns in Ghana. International Journal of Mathematics and Mathematical Sciences. https://doi.org/10.1155/2018/7016792 
Ati Retna Sari ${ }^{1}$, Doni Wirshandono Yogivaria ${ }^{2}$, Nilai Tukar Dan Inflasi Terhadap Return Saham Melalui Kinerja Keuangan

Okechukwu, Mbadike Geoffrey, O. (2019). Effects of Exchange Rate, Interest Rate, and Inflation on Stock Market Returns Volatility in Nigeria. International Journal of Management Science and Business Administration, Volume 5, Pages 38-47.

Ramadhan, Z., \& Dhea, A. (2019). Faktor-faktor yang Mempengaruhi Return Saham (Studi Pada Perusahaan Sektor Kosmetik dan Keperluan Rumah Tangga yang Terdaftar di BEI. Journal of Applied Business and Economi.

Rudianto. (2013). Akuntansi Manajemen Informasi UntukPpengambilan Keputusan Strategis. Erlannga.

Tandelilin, E. (2017). Pasar Modal Manajemen Portofolio E Investasi. PT. Kanisius. 